\title{
Growth, Strobile Yield, and Quality of Four Humulus lupulus Varieties Cultivated in a Protected Open-sided Greenhouse Structure
}

\author{
Brian J. Pearson ${ }^{1,4}$, Richard M. Smith ${ }^{2}$, and Jianjun Chen ${ }^{3}$ \\ Department of Environmental Horticulture, University of Florida, \\ Mid-Florida Research and Education Center, 2725 South Binion Road, \\ Apopka, FL 32703
}

Additional index words. Hops, neomexicanus, lupulin, 'Columbus', 'Chinook', 'Neo1', 'Amalia'

Abstract. Hops (Humulus lupulus) is a perennial, herbaceous crop cultivated for its strobiles, or cones, which contain a resinous compound used for flavoring and aroma in food, tea, and beer. The United States is the second largest global producer of hops with greater than 15,000 ha in production. Increased demand for hop products has recently resulted in production of hops in nontraditional production areas (non-Pacific northwest U.S. region). To examine cultivation potential of hops within the southeastern United States, 60 hop rhizomes consisting of four varieties were transplanted into native, deep sand soil (Candler and Tavares-Millhopper soil series) within a protected, open-sided greenhouse and evaluated for growth, strobile yield, and brewing values for a period of 2 years. Plant bine length was recorded weekly for 20 weeks throughout year 1 with mean bine lengths of 609, 498, 229, and $221 \mathrm{~cm}$ at harvest for 'Chinook', 'Columbus', 'Amalia' and 'Neo1', respectively. Mean harvested strobile dry weight recorded for year 1 was 21.2, 17.9, 9.0, and 8.2 g/plant for 'Columbus', 'Chinook', 'Neo1' and 'Amalia', respectively. With the exception of 'Neo1', mean strobile mass was lower for all cultivars during year 2 with 16.6, 10.3, 25.8, and 2.6 g/plant for 'Columbus', 'Chinook', 'Neo1' and 'Amalia', respectively. Alpha acid concentrations by percentage strobile mass for year 1 were $6.8 \%, 9.7 \%, 3.8 \%$, and $4.3 \%$ for 'Columbus', 'Chinook', 'Amalia', and 'Neo1', respectively. Alpha acids varied year 2 with concentrations of $4.8 \%, 10.4 \%$, and $5.6 \%$ for 'Columbus', 'Chinook', and 'Neo1', respectively. Findings support viability of hop production in the southeastern United States and establish the benchmark for future varietal trialing investigations.

Humulus lupulus, or hops, is a long-lived, perennial, herbaceous agricultural crop commonly propagated from rhizomes and cultivated for its strobiles. The strobiles, or cone-like female inflorescences, produce a crystalline compound, lupulin, which imparts unique bittering, flavoring, and aromatic qualities to finished beer products (Almaguer et al., 2014; Burgess, 1964). Lupulin contains both alpha and beta acids, principle compounds responsible for the bittering and aromatic characteristics of hops. Alpha and beta acid concentrations are quantified postharvest and used in beer recipe design. Concentrations of these acids are largely dependent on plant age, cultivar, and environmental conditions associated with production location (Barth et al., 1994). In addition, hops contain a large diversity of volatile oils which impart a unique array of aromas described as woody,

Received for publication 8 Feb. 2016. Accepted for publication 18 Apr. 2016.

${ }^{1}$ Assistant Professor

${ }^{2}$ Biological Scientist

${ }^{3}$ Professor

${ }^{4}$ Corresponding author. E-mail: bpearson@ufl.edu. citrusy, floral, earthy, lemony, spicy, piney, fruity, or sweet (Almaguer et al., 2014). Of the vast array of volatile oils found in hops, caryophyllene, humulene, and myrcene are often regarded as the most significant and thus are conventionally reported postharvest during sale. Although considerable research has been conducted on volatile oils of hops, disagreement remains regarding the specific compounds responsible for sensory qualities in finished beer products (Goiris et al., 2014; Hofte et al., 1998; Van Opstaele et al., 2012). In addition to imparting unique bittering and aromatic qualities to finished beer products, hops confer antibacterial properties to beer, assist in sterilization and precipitation of nitrogenous compounds in wort, and act as a filtering aid in the hop back (Moritz and Morris, 1891). Diversity of hop varieties and their associated characteristics continues to foster interest in breeding and exploration for wild hop genomes (Lombard et al., 2014; Small, 1980).

Germany leads worldwide production of hops, yielding $41 \%$ of global production at $38,399,769 \mathrm{~kg}$ on 17,308 ha (George, 2014). The United States is the second largest global producer of hops with $34 \%$ of global production at $32,203,697 \mathrm{~kg}$ on an estimated 15,738 ha. Processing and production of hops within the United States is centered in the Pacific Northwest with Washington, Oregon, and Idaho being the largest producers. In 2014, Washington produced 79\% of the nation's hops on 11,678 ha averaging $2,170 \mathrm{~kg} \cdot \mathrm{ha}^{-1}$. Production outside of the Pacific Northwest accounts for only $2 \%$ of commercial acreage in the United States (USDA, 2015). However, interest in cultivation of hops outside of the Pacific Northwest region has continued to increase as a result of increased demand for craft beer products compounded by interest for locally sourced agricultural commodities (Tremblay and Tremblay, 2011). Although available data are limited, strobile yields from cultivation in nontraditional areas are lower than values reported for the Pacificnorthwest U.S. region with dry weight of 1350, 540, 225, and $352 \mathrm{~kg} \cdot \mathrm{ha}^{-1}$ from 'Cascade' hops cultivated in New York, Michigan, Vermont, and the Appalachian Mountain region of North Carolina, respectively (Davis, 2014). In 2007, a hop shortage caused prices to rise sharply amounting to a $20 \%$ increase for commonly grown varieties and an $80 \%$ increase for specialty varieties (Welch, 2007). Record hop prices coupled with increased demand for locally produced agricultural products has led to establishment of hop production in nontraditional areas (non-Pacific northwest U.S. region). Economic analysis of small-scale (0.1 ha) hops cultivation within North Carolina indicates a breakeven-price of between $\$ 22$ and \$5 per kg for dry strobile yield of between 300 and $600 \mathrm{~g} /$ plant, respectively (Bullen and Austin, 2014). The number of craft breweries operating in the southeastern United States has increased dramatically in response to demand, with a $50 \%$ increase in Florida between 2011 and 2013 (Brewers Association, 2015). Sale of craft beer products in Florida totaled \$875.8 million during 2013. Cultivation of hops within Florida or throughout much of the far southeastern United States for both local and national sale; however, has not been evaluated.

Hops require short days to flower and are primarily cultivated between $35^{\circ}$ and $55^{\circ}$ latitude where the plant benefits from moderate temperature and rainfall, with optimal conditions reported between $45^{\circ}$ and $50^{\circ}$ latitude (Hieronymus, 2012). Optimal photoperiod within this geographical range has been cited (Davis and King, 2012) as one of the most significant factors contributing to hop production success. Thomas and Schwabe (1969) examined the influence of photoperiod on hop growth and development within a controlled greenhouse environment and found inflorescence development was maximized at $16 \mathrm{~h}$ daylength; however, response was dependent on cultivar. Results support the optimal reported geographic range for hop cultivation between $35^{\circ}$ and $55^{\circ}$ latitude based on daylength; however, additional investigations are necessary to 
ascertain relationships between photoperiod and inflorescence development.

Germplasm obtained from plant collection efforts have resulted in commercial release of hops native to North America (H. lupulus var. neomexicanus). These varieties, native to the southwestern United States, contain unique genetic diversity not found in conventionally bred, commercially popular Eurasian varieties (Smith et al., 2006). Given their native range and unique characteristics, $H$. lupulus var. neomexicanus varieties may perform better in the southern United States where high temperatures are common and limited variations in seasonal photoperiod exist. The objective of this study was to examine the influence of cultivar among two U.S. native (H. lupulus var. neomexicanus) and two U.S. nonnative (H. lupulus var. lupulus) varieties on growth, quality, strobile yield, lupulin acid concentration, and volatile oil profile when cultivated in an open-sided, greenhouse in Florida. Results from this work will provide hop producers with a greater understanding of the efficacy of hop production within the nontraditional, far southeastern U.S. region. Further, differences among cultivars may establish baseline data that may be used for varietal trial experiments in future investigations.

\section{Materials and Methods}

Fifteen rhizomes of two nonnative U.S varieties (H. lupulus var. lupulus), 'Chinook' and 'Columbus', along with fifteen rhizomes of two native U.S. varieties (H. lupulus var. neomexicanus), 'Amalia' and 'Neo1', were purchased (RNV Enterprises in Yakima, WA) and transplanted on 3 May 2014 into a $450 \mathrm{~m}^{2}$ open-sided, greenhouse located in Apopka, FL (lat. $28^{\circ} 38^{\prime} \mathrm{N}$, long. $81^{\circ} 33^{\prime} \mathrm{W}$ ). Rhizomes were transplanted at a depth of $5.4 \mathrm{~cm}$ into $0.3 \mathrm{~m}^{2}$ ground plots containing Candler and Tavares-Millhopper fine sand soil (National Resources Conservation Service, 2011) amended with compost (Mushroom Compost; Monterey Mushrooms, Zellwood, FL) at a rate of $0.04 \mathrm{~m}^{3}$ per plot. Plots were arranged into 10 rows of 6 , oriented north to south. A metal wire spanning the width of the greenhouse, $\approx 10 \mathrm{~m}$, was installed $3 \mathrm{~m}$ above each row. Two pieces of twine were installed from the ground to the overhead metal wire within each plot to provide support for the hops' antrorse, clockwise bine growth. Three to four bines were trained onto each piece of twine within each plot. All remaining plant growth was ended near the ground through manual harvest. Slow-release fertilizer $(18 \mathrm{~N}-2.6 \mathrm{P}-6.6 \mathrm{~K}$ Nutricote Type 100, Florikan, Sarasota, FL) was applied to each plot at a rate of $16 \mathrm{~g} \mathrm{~N}$ per $0.3 \mathrm{~m}^{2}$ plot 3 weeks after transplanting year 1 and 2 weeks after plant emergence (WAE) during year 2 . In addition, a soluble fertilizer (10N-4.4P-4.2K All Purpose Liquid Fertilizer; BGI, Boynton Beach, FL) was applied at a rate of $1.8 \mathrm{~g} \mathrm{~N}$ per $0.3 \mathrm{~m}^{2}$ plot at 4,6 , and 8 weeks after transplant for year 1 or emergence from dormancy for year 2. Environmental weather data were collected from the onsite
Florida Automated Weather Network station (Florida Automated Weather Network, 2011).

Three microirrigation emitters (Shrubbler; Antelco, Longwood, FL) were purchased and installed within each plot. Emitters were calibrated to deliver $3 \mathrm{~L}$ per plot and to ensure irrigation distribution uniformity of $\geq 90 \%$ (Warrick, 1983) during each watering event. Irrigation events were controlled by a programmable irrigation time clock (Sterling 12; Superior Controls Co., Inc., Valencia, CA) programmed to apply water every other day.

Throughout year 1, bine length was recorded each week beginning 1 week after transplant (WAT) and continued until termination of the experiment 20 WAT. Strobiles were harvested when mature, based on visual and mechanical determination. Strobiles were harvested at the strig to maintain plant leaf area and placed in a room with temperature and humidity maintained at $22{ }^{\circ} \mathrm{C}$ and $60 \%$, respectively. Once constant dry weight was obtained, strobile mass was measured, recorded, and stored in a sealed bag and placed within a freezer. Strobile quality was assessed through visual evaluation using a Likert scale with $1=$ poor strobile leaf quality and structure and $3=$ high strobile leaf quality and structure. After harvest of all strobiles, a randomized subsample was collected and shipped to a private, independent laboratory (Alpha Analytics, Yakima, WA) for organic acid concentration and volatile oil quantification through a high-pressure liquid chromatography technique. Bine length was not quantified during year 2; however, strobile yield, strobile quality ratings, and organic acid and volatile oil concentrations were recorded.

The experiment was arranged as an incomplete randomized block design with hop cultivar randomly assigned within block with six plants per block and 15 replicates per cultivar. A total of 10 blocks containing six plants each were arranged in a north-south orientation within the greenhouse for a total of 60 plants (Table 1). This experimental design was selected given physical greenhouse space limitation where block size was smaller than the number of treatments imposed (Dean and Voss, 1999). Statistical analysis of bine length was conducted using the PROC GLM procedure in SAS with mean separation by Duncan's multiple range test. Nonparametric analysis of variance of strobile quality was conducted using the PROC NPAR1WAY procedure (Kruskal-Wallis) in SAS. Statistical tests were considered to be significant if $P<0.05$.

\section{Results and Discussion}

Environmental data. Mean daily temperatures ranged from 13.7 to $30.2^{\circ} \mathrm{C}$ for years 1 and 2 . Relative humidity remained high throughout both years with a mean of $80.4 \%$. Daily light integral ranged from 86.3 to $704 \mu \mathrm{mol} \cdot \mathrm{m}^{-2} \cdot \mathrm{d}^{-1}$ with a mean of $436.3 \mu \mathrm{mol} \cdot \mathrm{m}^{-2} \cdot \mathrm{d}^{-1}$ over both years. Daylength ranged from a minimum of $11 \mathrm{~h} 55 \mathrm{~min}$ on
13 Mar. 2015 to maximum of $13 \mathrm{~h} 58 \mathrm{~min}$ on 21 June 2014 and 2015. Although photoperiod was not evaluated as a treatment in this experiment, similar daylength was imposed as a treatment factor on inflorescence development by Thomas and Schwabe (1969). Authors reported successful flower induction at $14 \mathrm{~h}$ daylengths; however, inflorescence was maximized for tested cultivars (Fuggle, CC 31, and New York Hop) when 16 h daylengths were imposed.

Bine length. Not all rhizomes survived transplanting during year 1. Clonal propagules of 12 'Amalia', 6 'Chinook', 5 'Columbus', and 3 'Neo1' transplants were prepared and transplanted into the protected structure to replace plants, which did not have adventitious shoot growth emerge from the soil within 4 WAT during year 1 . Poor performance was likely a result of poor rhizome quality, disease, or both. Despite a slightly later planting date of clonal propagules (6 WAT) to serve as replacements for ended plants, bine length was not significantly different when compared with those propagated from rhizomes; thus, data were combined for analysis. Hop bine length was generally linear for both 'Amalia' and 'Neol' varieties but logarithmic for 'Columbus' and 'Chinook' (Fig. 1). Bine length was significantly different among cultivars beginning 2 WAT where 'Columbus' and 'Chinook' bines were longer than 'Amalia' or 'Neo1'. Growth trends remained similar throughout duration of year 1 . At termination of year 1, 20 WAT, bine length of 'Columbus' and 'Chinook', were $\approx 2.5$ fold greater than either 'Amalia' or 'Neol'. Although bine length was not quantified during year 2, similar bine length and plant structure trends among cultivars were observed. Given their low bine length, 'Amalia' and 'Neol' varieties may be better suited for low trellis production systems where reduced bine length is desirable and specialized equipment is not required for harvest (Darby, 2007; Seigner et al., 2008).

Strobile yield. Strobile harvest began 8 WAT for 'Columbus' and 'Chinook' and 16 WAT for 'Amalia' and 'Neo1' during year 1 and $\approx 9$ WAE for all cultivars in year 2 . Dissimilar harvest dates among cultivars in year 1 suggest plants were not uniformly established and mature. Strobile dry weight was 21.2, 17.9, 9.0, and $8.2 \mathrm{~g} /$ plant for 'Columbus', 'Chinook', 'Neo1', and 'Amalia', respectively (Fig. 2). 'Columbus' and 'Chinook' cultivars produced $\approx 2.3$-fold greater strobile mass than 'Amalia' and 'Neo1'. Strobile dry weight decreased between 1.3and 3.5-fold for 'Columbus', 'Chinook', and 'Amalia' year 2 with a mean strobile mass of 16.6, 10.3, and $2.6 \mathrm{~g} /$ plant for 'Columbus', 'Chinook', and 'Amalia', respectively (Fig. 2). Reduced yields among these cultivars suggests warm, mild winters experienced in Central Florida, which prevent or reduce winter dormancy in selected crops, may degrade or prevent long-term strobile production and acceptable plant performance. A lack of comparable examinations 
Table 1. Incomplete randomized block design of four Humulus lupulus cultivars (Columbus, Chinook, Amalia, and Neo1) cultivated within a greenhouse structure in Apopka, FL. ${ }^{z}$

\begin{tabular}{|c|c|c|c|c|c|c|c|c|c|}
\hline$\overline{\text { Block } 1}$ & Block 2 & Block 3 & Block 4 & Block 5 & Block 6 & Block 7 & Block 8 & Block 9 & Block 10 \\
\hline$\overline{\mathrm{Neo} 1}$ & Columbus & Chinook & Amalia & Neol & Amalia & Neol & Chinook & Columbus & Columbus \\
\hline Columbus & Amalia & Neo1 & Chinook & Columbus & Amalia & Amalia & Amalia & Chinook & Neol \\
\hline Neol & Neo1 & Chinook & Amalia & Neo1 & Columbus & Chinook & Chinook & Columbus & Amalia \\
\hline Columbus & Chinook & Amalia & Columbus & Columbus & Chinook & Columbus & Neo1 & Chinook & Neo1 \\
\hline
\end{tabular}

${ }^{\mathrm{z}}$ Blocks measured $\approx 11 \mathrm{~m}$ long by $1 \mathrm{~m}$ wide.

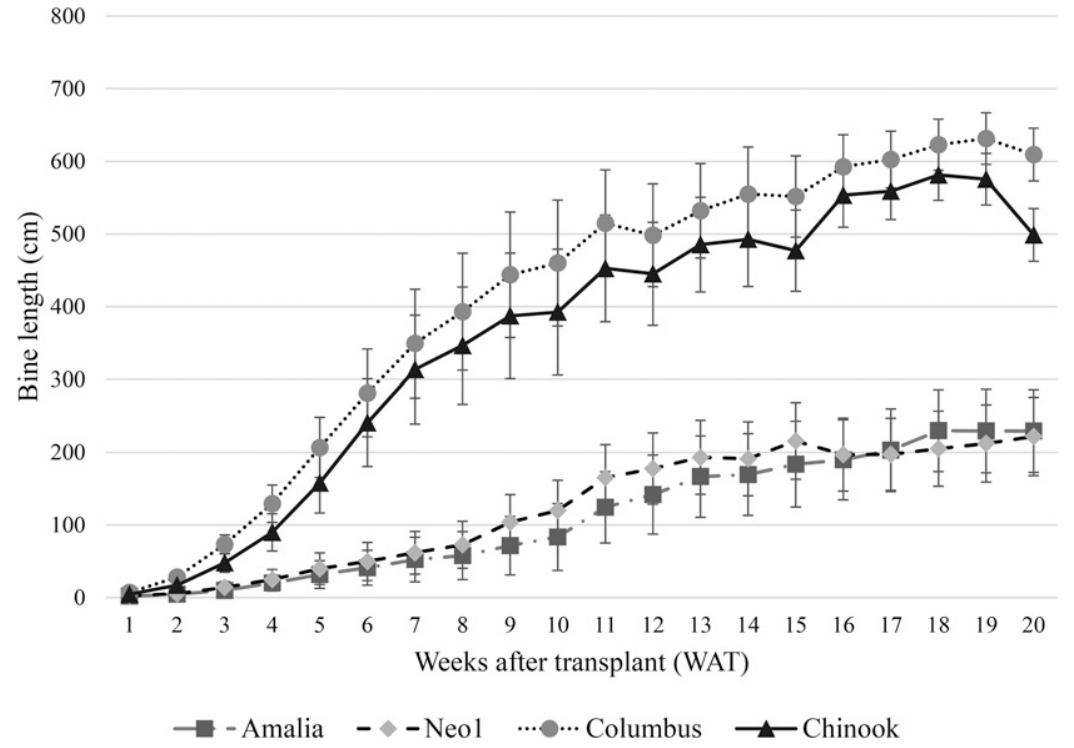

Fig. 1. Bine length of 'Amalia', 'Neo1', 'Columbus', and 'Chinook' hops (Humulus lupulus) cultivated in an open-sided greenhouse in Central Florida between 3 May 2014 and 20 Sept. 2014. Mean separation by Duncan's multiple range test $(P \leq 0.05 ; \mathrm{n}=15)$. Error bars represent standard error of the mean.

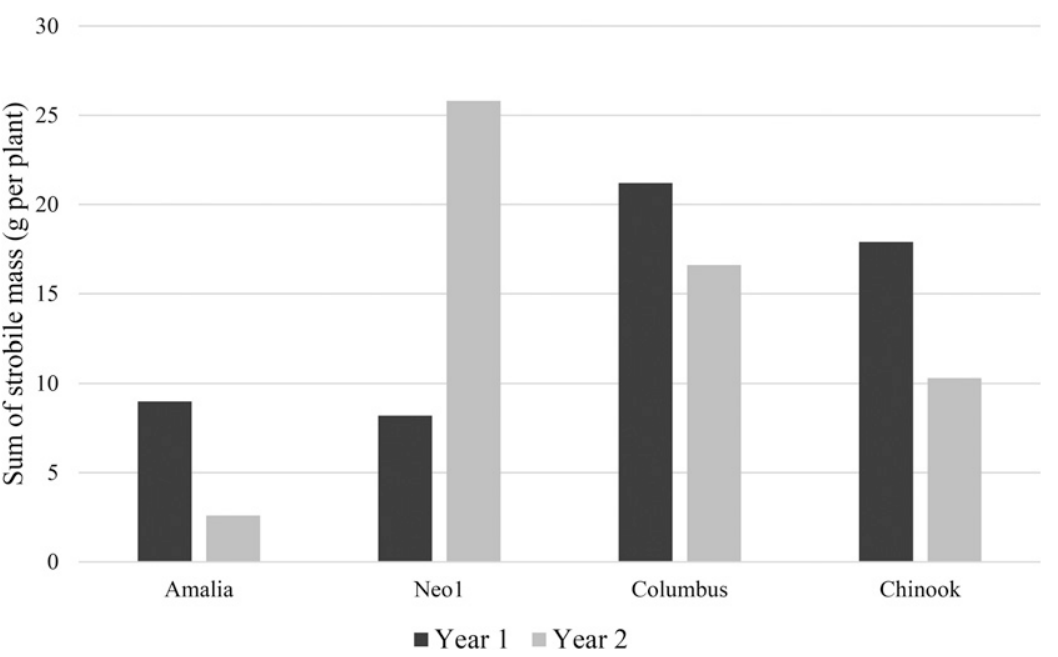

Fig. 2. Mass of 'Amalia', 'Neo1', 'Columbus', and 'Chinook' strobiles harvested from hops $(\mathrm{n}=15)$ (Humulus lupulus) cultivated in an open-sided greenhouse in Central Florida between 3 May 2014 and 20 Sept. 2014 (year 1) and between 13 Mar. 2015 and 25 Sept. 2015 (year 2).

and long-term data on hop production in Florida prevents elucidation on the influence of limited dormancy on strobile production. Unlike other cultivars tested, strobile mass of 'Neo1' during year 2 increased 3.1-fold to 25.8 g/plant. Results suggest 'Neo1' may not be negatively influenced by local environmental production conditions and is better suited for long-term commercial production within Central Florida than 'Columbus', 'Chinook', or
Strobile quality. Mean strobile quality ratings for year 1 were $2.2,2.5,1.8$, and 2.1 for 'Columbus', 'Chinook', 'Amalia', and 'Neo1', respectively, and were significantly different among cultivar. Unlike year 1 , strobile quality throughout year 2 was similar among cultivar at 2.3, 2.5, 2.6, and 2.2 for 'Columbus', 'Chinook', 'Amalia', and 'Neo1', respectively. Slower establishment of neomexicanus varieties may have resulted in the significantly lower strobile quality observed during year 1. Influence of cultivar on establishment of hops is undocumented; however, bine length, strobile harvest date, and quality data collected as part of this 2-year study suggests 'Columbus' and 'Chinook' cultivars may establish more rapidly than either 'Amalia' or 'Neol' given similar environmental conditions and thus may be responsible for differences between consecutive years.

Brewing values. Alpha acid concentrations by strobile dry weight for year 1 were $6.8 \%, 9.7 \%, 3.8 \%$, and $4.3 \%$ for 'Columbus', 'Chinook', 'Amalia', and 'Neol', respectively (Table 2). Beta acid concentrations during year 1 were $2.7 \%, 2.1 \%, 3.4 \%$, and $2.6 \%$ for 'Columbus', 'Chinook', 'Amalia', and 'Neo1', respectively. During year 2, alpha acid concentrations increased for both 'Chinook' and 'Neo1' to $10.4 \%$ and $5.6 \%$, respectively, but decreased in in 'Columbus' to $4.8 \%$ (Table 2). Beta acid concentrations by strobile dry weight for year 2 were similar to those reported for year 1 at $2.8 \%, 2.5 \%$, and $2.4 \%$ for 'Columbus', 'Chinook', and 'Neo1', respectively. Low strobile yield during year 2 from 'Amalia' precluded quantification of either alpha or beta acid concentrations. Alpha and beta acid concentrations were below mean values reported by Hop Growers of America (2009) for both years of this investigation; however, increased concentrations observed in both 'Chinook' and 'Neo1' strobiles between consecutive years suggest strobiles from these cultivars will likely attain similar values to those reported by Hop Growers of America (2009) as plants mature and age (Barth et al., 1994). Brewing value of strobiles remain high irrespective of acid concentrations as bittering and aromatic qualities imparted by hops in finished beer and food products are determined through algorithmic computation of strobile mass and acid concentration during recipe design and thus are not solely dependent on strobile acid concentrations.

Volatile oil concentrations were quantified from strobiles harvested from 'Columbus' and 
Table 2. Alpha and beta acid concentrations by percentage of Humulus lupulus strobile mass harvested from four cultivars (Columbus, Chinook, Amalia, and Neo1) cultivated within a greenhouse structure in Apopka, FL. ${ }^{z}$

\begin{tabular}{|c|c|c|c|c|c|c|}
\hline \multirow[b]{2}{*}{ Cultivar } & \multicolumn{2}{|c|}{ Yr 1} & \multicolumn{2}{|c|}{ Yr 2} & \multicolumn{2}{|c|}{ Reference value ${ }^{y}$} \\
\hline & $\begin{array}{c}\text { Alpha } \\
\text { acids (\%) }\end{array}$ & $\begin{array}{c}\text { Beta } \\
\text { acids }(\%)\end{array}$ & $\begin{array}{c}\text { Alpha } \\
\text { acids (\%) }\end{array}$ & $\begin{array}{c}\text { Beta } \\
\text { acids (\%) }\end{array}$ & $\begin{array}{c}\text { Alpha } \\
\text { acids (\%) }\end{array}$ & $\begin{array}{c}\text { Beta } \\
\text { acids }(\%)\end{array}$ \\
\hline Columbus & 6.8 & 2.7 & 4.8 & 2.8 & $14-18$ & $4.5-5.5$ \\
\hline Chinook & 9.7 & 2.1 & 10.4 & 2.5 & $12-14$ & $3-4$ \\
\hline Amalia & 3.8 & 3.4 & $\mathrm{n} / \mathrm{a}$ & $\mathrm{n} / \mathrm{a}$ & $5.5-9$ & $4.2-8.3$ \\
\hline Neo1 & 4.3 & 2.6 & 5.6 & 2.4 & $7-9$ & $3-3.3$ \\
\hline
\end{tabular}

${ }^{\mathrm{z}}$ Means of $75 \mathrm{~g}$ strobile subsample collected from four hop cultivars $(\mathrm{n}=15)$.

${ }^{y}$ Alpha and beta acid concentrations by percentage of strobile mass reported by Hop Growers of America (2009) for 'Columbus' and 'Chinook' and RNV Enterprises (2014) for 'Neo1' and 'Amalia'.

Table 3. Volatile oil concentrations by percentage of Humulus lupulus strobile mass from two cultivars (Columbus and Chinook) cultivated within a greenhouse structure in Apopka, FL. ${ }^{z}$

\begin{tabular}{|c|c|c|c|c|c|c|}
\hline \multirow[b]{2}{*}{ Volatile oil } & \multicolumn{2}{|c|}{ Yr 1} & \multicolumn{2}{|c|}{ Yr 2} & \multicolumn{2}{|c|}{ Reference value ${ }^{y}$} \\
\hline & Columbus & Chinook & Columbus & Chinook & $\overline{\text { Columbus }}$ & Chinook \\
\hline Caryophyllene (\%) & 14.6 & 11.9 & 21.4 & $\mathrm{n} / \mathrm{a}$ & $9-11$ & $9-11$ \\
\hline Humulene $(\%)$ & 18.9 & 26.6 & 38.5 & $\mathrm{n} / \mathrm{a}$ & $12-18$ & $18-23$ \\
\hline Myrcene $(\%)$ & 38.1 & 22.2 & 10.3 & $\mathrm{n} / \mathrm{a}$ & $40-50$ & $35-40$ \\
\hline
\end{tabular}

${ }^{\mathrm{z}}$ Means of $150 \mathrm{~g}$ strobile subsample collected from two hop cultivars $(\mathrm{n}=15)$.

${ }^{\mathrm{y}}$ Volatile oil concentrations by percentage strobile mass reported by Hop Growers of America (2009).

'Chinook' during year 1 and only from 'Columbus' during year 2. Caryophyllene concentrations found in strobiles harvested from 'Columbus' were $14.6 \%$ and $21.4 \%$ by weight for year 1 and 2, respectively (Table 3 ). Similar increases were observed in humulene content for 'Columbus' where concentrations increased from $18.9 \%$ to $38.5 \%$ between year 1 and 2. Both caryophyllene and humulene concentrations were greater than the range of values reported by Hop Growers of America (2009) for 'Columbus' and 'Chinook' (Table 3). Myrcene concentrations were below the reported range of values (Hop Growers of America, 2009) for both cultivars; observed relationships between volatile oils were expected given the inversely proportional relationship that exists between myrcene and humulene (Howard et al., 1957). Caryophyllene and humulene are desirable compounds in hops given the unique sensory qualities they impart in finished food and beer products. Although volatile oil profiles among cultivar are well documented, additional research examining the influence of postharvest technique as well as the specific compounds responsible for sensory qualities in finished beer products is necessary.

\section{Conclusion}

Differences in growth, quality, yield, and organic acid and volatile oil concentrations among tested cultivars were observed throughout this 2-year study. Differences in bine length, strobile harvest date, and quality data between year 1 and 2 suggests 'Columbus' and 'Chinook' cultivars may establish more rapidly than either 'Amalia' or 'Neo1' given similar environmental conditions. Despite a likely longer establishment period, strobile yield of 'Neol' increased year 2 whereas yield for all other tested cultivars decreased. Given hops are cultivated for strobile production, results support selection of 'Neo1' for production in the southeastern U.S. region. Given documented relationships between daylength and hop inflorescence, extension of photoperiod may increase bine length and strobile yield; however, relationships between daylength and hop growth are not conclusive given limited available research. Additional research examining a greater array of hop cultivars as well as the influence of daylength is necessary to aid in the development of commercial production recommendations for the southeastern U.S. region.

Alpha and beta acid concentrations of strobiles were below reported values among all cultivars. Despite this, however, organic acid concentrations generally increased between consecutive years and thus may approach reported values with additional cultivation time and increased plant maturity. Concentrations of caryophyllene and humulene were at or above reported values for 'Columbus' and 'Chinook'. Results indicate local environmental production conditions may enhance concentrations of these vital volatile organic oils and enhance sensory qualities in finished beer products.

Hop production within a semicontrolled greenhouse structure in the southeastern United States is possible based on research findings collected from this 2-year study. Additional studies examining hop cultivation using a traditional tall trellis system is necessary to further elucidate the influence of production system on hop growth and strobile yield. Strobile yield, although reduced when compared with the traditional production regions in the Pacific Northwestern United States, can help meet the rapidly increasing strobile demand resulting from growth in the craft beer marketplace. In addition, recent trends in marketing of locally produced agricultural products may result in greater appeal to local craft brewers than strobiles produced in traditional regions. Low yields reported in this study challenge the economic feasibility for commercial production in the far southeastern United States based on economic estimates developed for North Carolina. Additional research examining the economic value of hops cultivated in the far southeastern United States coupled with research focused on the potential improvement of strobile yield are needed to accurately determine viability of commercial hop production within this region.

\section{Literature Cited}

Almaguer, C., C. Schönberger, M. Gastl, E.K. Arendt, and T. Becker. 2014. Humulus lupulus - a story that begs to be told. A review. J. Inst. Brew. 120:289-314.

Barth, H.J., C. Klinke, and C. Schmidt. 1994. The hop atlas: The history and geography of the cultivated plant. Joh. Barth \& Sohn, Nuremberg, Germany.

Brewers Association. 2015. State craft beer statistics. 18 Jan. 2015. <https://www.brewersassociation. org/statistics/by-state/>.

Bullen, G. and R. Austin. 2014. Enterprise budget: Small-scale commerical hops production in North Carolina. North Carolina State Univ., Raleigh, NC.

Burgess, A. 1964. Hops: Botany, cultivation, and utilization. Interscience, New York, NY.

Darby, P. 2007. The UK hop breeding programme: A new site and new objectives, Tettnang, Germany. (Intl. Hop Growers' Convention).

Davis, J. 2014. Growing hops in the southeast, Afton, VA. (Virginia Hops Wkshp.).

Davis, J. and S. King. 2012. Hop production in North Carolina. North Carolina State Univ., Mills River, NC.

Dean, A. and D. Voss. 1999. Design and analysis of experiments. Springer, New York, NY

Florida Automated Weather Network. 2011. Florida Automated Weather Network. 18 Jan. 2015. $<$ http://fawn.ifas.ufl.edu/>.

George, A. 2014. 2014 Hop growers of America statistical report. Moxee, WA.

Goiris, K., B. Jaskula-Goiris, E. Syryn, F. Van Opstaele, G. De Rouck, G. Aerts, and L. De Cooman. 2014. The flavoring potential of hop polyphenols in beer. J. Amer. Soc. Brew. Chem. 72:135-142.

Hieronymus, S. 2012. For the love of hops: The practical guide to aroma, bitterness and the culture of hops. Brewers Publications, Boulder, $\mathrm{CO}$.

Hofte, A.J.P., R.A.M. van der Hoeven, S.Y. Fung, R. Verpoorte, U.R. Tjaden, and J. vad der Greef. 1998. Characterization of hop acids by liquid chromatography with negative electrospray ionization mass spectrometry. J. Amer. Soc. Brew. Chem. 56:118-122.

Hop Growers of America. 2009. Hop variety manual. Moxee, WA.

Howard, G.A., C.A. Slater, and A.R. Tatchell. 1957. Chemistry of hop constituents XI. Some observations on the isomerization of humulone. J. Inst. Brew. 63:237-248.

Lombard, K., K. McCarver, F.J. Thomas, R. Acharya, and T. Bates. 2014. What's hop'pening in northwest New Mexico? Hops (Humulus lupulus) trials summary 2009 to 2014, Orlando, FL. (Amer. Soc. Hort. Sci.).

Moritz, E. and G. Morris. 1891. A text-book of the science of brewing. E. \& F.N. Spon, London, UK.

National Resources Conservation Service. 2011. National Resources Conservation Service. 18 Jan. 2015. <http://websoilsurvey.nrcs.usda.gov/ app/HomePage.htm>.

R.N.V. Enterprises. 2014. Hop variety descriptions. Yakima, WA. 
Seigner, E., A. Lutz, K. Oberhollenzer, R. Seidenberger, S. Seefelder, and F. Felsenstein. 2008. Breeding of hop varieties for the future, Ghent, Belgium (Second Intl. Humulus Symp.).

Small, E. 1980. The relationships of hop cultivars and wild variants of Humulus lupulus. Can. J. Bot. 58:676-686.

Smith, J.M., J.M. Oliphant, and K.E. Hummer. 2006. Plant exploration for native Hop in the American southwest. Plant Genet. Resour. Newsl. 147:1-9.
Thomas, G.G. and W.W. Schwabe. 1969. Factors controlling flowering in hop (Humulus lupulus L). Ann. Bot. 33:781-793.

Tremblay, C.H. and V.J. Tremblay. 2011. Recent economic developments in the import and craft segment of the US brewing industry. Oxford Univ. Press, Oxford, UK.

USDA. 2015. Crop Values 2014 Summary. Washington, DC.

Van Opstaele, F., B.D. Causmaecker, G. Aers, and L.D. Cooman. 2012. Characterization of novel varietal floral hop aromas by headspace solid phase microextraction and gas chromatography-mass spectrometry/ olfactometry. J. Agr. Food Chem. 60:1227012281

Warrick, A.W. 1983. Interrelationships of irrigation uniformity terms. J. Irrig. Drain. Eng. 109:317-332

Welch, D. 2007. Hops shortage likely to boost price of beer, Morning Edition, Natl. Public Radio, Washington, DC. 